\title{
Patrimonio gastronómico de la Provincia de Yariguíes (Santander, Colombia)
}

research paper

\section{Gastronomical heritage of the Provincia de Yariguies (Santander, Colombia)}

\author{
Luz Marina Rodríguez-Martínez ${ }^{1}$ \\ Universidad Autónoma de Bucaramanga, Colombia \\ (D) https://orcid.org/0000-0002-0803-6679
}

\author{
Indira Andrea Quiroga Dallos² \\ Docente Universidad Autónoma de Bucaramanga, Colombia \\ http://orcid.org/0000-0002-6511-9534
}

\begin{abstract}
Resumen: Ante la evidente pérdida de las tradiciones gastronómicas en Santander, esta investigación tiene como objetivo principal contribuir a la salvaguardia del patrimonio gastronómico de la provincia de Yariguíes (o provincia de Mares hasta 2019), con base en la identificación, la caracterización y el análisis de sus principales componentes. Desde un enfoque de investigación formativa, la metodología empleada se basó en la revisión de fuentes secundarias sobre la gastronomía y la cultura de los municipios San Vicente de Chucurí, Barrancabermeja, Betulia, El Carmen de Chucurí, Sabana de Torres y Puerto Wilches. Así mismo, se realizó un trabajo de campo en estos municipios, con el fin reconocer de modo crítico los usos gastronómicos propios de la región, los distintos productos y preparaciones más representativos. De esta forma se pudo identificar a las maestras de la cocina, a quienes se les hizo una entrevista semiestructurada con la que se pretendía conocer las costumbres, los usos y las tradiciones en las preparaciones, y los productos agrícolas más representativos de este territorio que forman parte de los platos tradicionales. Así mismo, se consultó sobre los ambientes culturales en torno a la comida tradicional y típica de esta provincia. Teniendo en cuenta esto, se encontró que en la provincia de Yariguíes existe variada gastronomía típica y tradicional. El oficio predominante es la pesca, particularmente con red y anzuelo, oficio que tienen los pobladores para generar ingresos y realizar sus preparaciones culinarias, con pescados como el bocachico, la dorada y el blanquillo. También se observó que los productos que se cultivan en esta región, como el aguacate, el ñame, la yuca, el plátano, entre otros, forman parte de los platos elaborados. La participación de familiares y amigos al ritmo de música y baile se evidencia en la dinámica gastronómica de la región. Finalmente, como acción para la salvaguardia se plantea la filmación de un documento audiovisual por medio del cual se registre y se facilite la divulgación de este patrimonio, y se reconozcan las características de los hallazgos, según los parámetros institucionales del patrimonio cultural inmaterial.
\end{abstract}

Palabras clave: patrimonio cultural; gastronomía; tradición; identidad cultural; Yariguíes; Festival, Maestras de la cocina

Recibido: 30/06/2019 | Aceptado: 27/03/2020 | Disponible en línea: 30/04/2020

Como citar este artículo: Rodríguez-Martínez L. M., y Dallos, I. A. Q. (2020). Patrimonio gastronómico de la Provincia de Yariguies (Santander, Colombia). Jangwa Pana, 19(2), 219 - 244. Doi: https://doi.org/10.21676/16574923.3478

Abstract: In view of the obvious loss of gastronomic traditions in Santander, the main objective of this research is to contribute to the safeguarding of the gastronomic heritage of the Province of Yariguíes (or

\footnotetext{
${ }^{1}$ Correo Electrónico: lrodrima@unab.edu.co

${ }^{2}$ Correo Electrónico: iquiroga91@unab.edu.co
} 
Province of Mares until 2019), based on the identification, characterization and analysis of its main components. From a formative research approach, the methodology used was based on the review of secondary sources on gastronomy and culture in the municipalities of San Vicente de Chucurí, Barrancabermeja, Betulia, El Carmen de Chucurí, Sabana de Torres and Puerto Wilches. Likewise, fieldwork was carried out in these municipalities in order to critically recognize the indigenous gastronomic uses, the different products and preparations and the identification of Teachers of the Kitchen to whom a semi-structured interview was applied where the customs were intended to be known, the uses and traditions in the preparations, also of the most representative agricultural products that are produced in this territory and that are part of the preparations of the traditional dishes, likewise consult about the cultural environments around the traditional and typical food of this Province. Taking into account the above, it was found that in the Yariguíes province there is a varied gastronomy typical and traditional, the predominant trade is fishing, particularly with a net and hook, a trade that the inhabitants have to generate income and make their culinary preparations with fish such as bocachico, bream and the tile. Likewise, the products grown in this region such as avocado, yam, yucca, banana, among others, are part of the dishes prepared. The participation of family and friends in unison of music and dance is evident in the dynamics gastronomic of the region. Finally, as an action for safeguarding, the preparation of an audiovisual document is proposed, through which the disclosure of the document is recorded and facilitated where the characteristics of the findings are recognized under the institutional parameters of the Intangible Cultural Heritage.

Keywords: Cultural heritage; gastronomy; tradition; identity cultural; cathedra; preserves. Teachers of the Kitchen

\section{Introducción}

Los estudios sobre gastronomía santandereana se centran en su mayoría en una valiosa información sobre recetas (Ordóñez, 2012; Sánchez y Sánchez, 2012). No obstante, aquí es necesario resaltar que no existe un diagnóstico serio sobre el estado de preservación de la cocina tradicional santandereana. Se tienen como referencias la publicación del libro La cocinanza comedida (De los Ríos, 2002) y del artículo "Salvaguarda del patrimonio cultural gastronómico santandereano" (Rodríguez-Martínez y Cáceres-Flórez, 2016), a los cuales debe sumarse la realización de los ejercicios de estudio para poder avanzar en un plan que propenda a la salvaguardia del patrimonio gastronómico.

La principal fuente de investigación en relación con la cultura alimentaria amerindia son los cronistas hispánicos ${ }^{3}$, que a pesar de su visión eurocéntrica y las limitaciones lingüísticas dieron cuenta y describieron en sus relatos algunas manifestaciones culinarias. Otra fuente importante son los relatos de viajeros que pasaron o estuvieron en el territorio nacional, principalmente durante los siglos XVIII y XIX ${ }^{4}$. Estudios sobre las raíces históricas de la alimentación y las cocinas colombianas pueden verse en los aportes de las investigaciones arqueológicas sobre la alimentación y el desarrollo de la agricultura en las poblaciones prehispánicas.

\footnotetext{
${ }^{3}$ Entre los cronistas merecen mención, por su importancia, fray Pedro Simón (1881), con sus Noticias historiales de la conquista de tierra firme en las Indias Occidentales; Bernal Díaz del Castillo (2010), autor de la Conquista de Nueva España; Gonzalo Fernández de Oviedo (1950), con su Sumario de la natural historia de las Indias, y Juan de Castellanos, con la cuarta parte de sus Elegías de varones ilustres de Indias (1857), que hace referencia la conquista de Bogotá, Tunja y pueblos aledaños, solo por mencionar algunos. ${ }^{4}$ Entre las crónicas, cabe destacar al cronista norteamericano Isaac Holton (1981) con La Nueva Granada: veinte meses en los Andes; a los franceses Gaspard Mollien (2007), con Viaje por la República de Colombia en 1823, Auguste Le Moyne (1969) con Viaje y estancia en la Nueva Granada, y Charles Saffray (1948), con Viaje a Nueva Granada; y los británicos Rosa Carnegie Williams (1990), con Un año en los Andes o aventuras de una lady en Bogotá y John Steuart (1989) y con su Narración de una expedición a la capital de la Nueva Granada y residencia allí de onces meses. Recordemos que uno de los títulos de la Biblioteca Básica de Cocinas Colombianas recoge todas las impresiones en torno a la cultura alimentaria que tuvieron los visitantes foráneos desde el siglo XVI hasta el XVII (Saldarriaga, 2012).
} 
Teniendo en cuenta lo anterior, y considerando la idea de emprender investigaciones que procuren la recuperación del patrimonio santandereano, el objetivo de este trabajo investigativo es aportar a la salvaguarda del patrimonio gastronómico de la provincia de Yariguíes (Santander) a través del rescate de la gastronomía, por medio de un material en el cual se caractericen los productos gastronómicos de dicha región.

En referencia particularmente a la cultura gastronómica, se presume que la industrialización de los alimentos, el consumo de bebidas azucaradas, la comida precocida, congelada y empacada, así como el cambio de estilos de vida y el aumento de población urbana en Colombia han aumentado el consumo de alimentos con preservantes, que son producidos bajo los lineamientos de la industria de alimentos. Por consiguiente, cocer una comida con el ritual necesario para la preparación culinaria con ingredientes naturales es un lujo de pocas ocasiones, o es un hecho que queda relegado a los restaurantes. Igualmente, ciertos platos conocidos como "típicos", representados en Santander - por ejemplo, el cabrito, el sancocho, la pepitoria, entre otros-, se convierten en comida "exótica" por su inusual sabor, presentación y forma de preparar, o definitivamente van desapareciendo de los paladares, debido a su poco consumo regular.

Los distintos intentos desde la academia y la literatura deben ser asumidos como un eslabón más en el proceso de la creación de hitos de identidad, los cuales son cruciales para la construcción del ser local que se constituye como parte del ser santandereano, y por ende del ser nacional. Estos procesos, además, deben tener cualidades tecnificadas y científicas, que procuren componentes teóricos y epistemológicos sólidos, de tal manera que los aspectos formales de identificación, valoración, gestión y salvaguardia del patrimonio se fortalezcan (Querol, 2010).

En Colombia, el rescate del patrimonio cultural gastronómico ha sido una prioridad de organismos gubernamentales como el Ministerio de Cultura y de instituciones académicas tanto privadas como públicas — entre estas el Instituto Colombiano de Antropología e Historia (ICANH) y las escuelas de historia, antropología, música, gastronomía y arquitectura de diversas instituciones de educación superior-, de tal forma que se han gestado en sinergia para encontrar la finalidad de salvaguardar el patrimonio material e inmaterial.

Ante la necesidad de continuar el proceso que se ha venido trabajando, cuyo objetivo es recuperar la identidad cultural del departamento de Santander y sus provincias (Rodríguez-Martínez y Cáceres-Flórez, 2016), surge la siguiente incógnita que, además, fungirá como pregunta rectora/problematizadora de esta investigación: ¿Cómo salvaguardar el patrimonio gastronómico de la provincia de Yariguíes en el departamento de Santander? Una respuesta pertinente, derivada del repaso de un estado de arte especializado en procesos de salvaguardia del patrimonio cultural a escala nacional y departamental, permite establecer que el proceso que se deberá conducir requiere una solución sistémica en la cual se tengan en cuenta diversos momentos de identificación, documentación, caracterización, análisis y preservación en un marco temporal amplio. 
Dicho esto, se evidencia la urgencia de seguir desarrollando acciones para rescatar y fortalecer los distintos aspectos que conforman los patrimonios culturales diversos del departamento de Santander, y se justifica cualquier proceso que conduzca a la salvaguarda del patrimonio inmaterial. Para el caso particular de las expresiones culturales de la provincia de Yariguíes, es objeto de salvaguardia aquello que transmitieron los indígenas que llevaban el mismo nombre de la provincia, quienes observaron, experimentaron e inventaron los modos de preparar alimentos para saciar el hambre y asegurar la supervivencia de sus familias, como también para llevar ofrendas a sus dioses y celebrar sus rituales principales y fiestas propias. Pero en esta dinámica también es necesario rescatar los elementos foráneos que llegaron tras las distintas migraciones de personas del interior del país, algunas promovidas por la economía asociada a la bonanza petrolera, y otras, provenientes de la zona norte ribereña - conocida también como zona costeña del país-, que arribaron motivadas a mejorar sus condiciones socioeconómicas o a huir del conflicto armado. Esto demuestra que no existe en sí una identidad nacional, sino más bien configuraciones regionales con las particularidades de las experiencias históricas propias, lo que genera una necesidad de reconocer, visibilizar e interpretar las distintas vivencias históricas y la herencia cultural, material e inmaterial que caracteriza a cada una de las colectividades.

Por esta razón, el programa de Gastronomía y Alta Cocina de la Universidad Autónoma de Bucaramanga (UNAB) está interesado en continuar trabajando en el rescate de aquellos bienes de interés cultural que competen a la alimentación y las expresiones culturales asociadas a esta, con lo cual se busca la forma de protegerlas a través de procesos de documentación y difusión.

De tal manera, como finalidades de esta investigación se propuso identificar la perspectiva sociocultural de la provincia Yariguíes asociada a la gastronomía, con base en la revisión de fuentes secundarias, y describir los saberes de quienes portan las tradiciones alimentarias y las principales preparaciones y productos que se consideran representativos en la región, y que se emplean en la comida tradicional. Este trabajo tiene un carácter ampliamente descriptivo, en la medida en que se considera que una forma de contribuir a la salvaguardia de este patrimonio es mediante su registro y divulgación por distintos medios.

\section{Patrimonio cultural y alimentación}

Siguiendo los parámetros de la Unesco, dentro de la categoría de patrimonio cultural se reconocen "los usos, representaciones, expresiones, conocimientos y técnicas - junto con los instrumentos, objetos, artefactos y espacios culturales que les son inherentes-" de los distintos grupos humanos y, sobre todo, que sean considerados representativos para estos, por lo que se los considera como parte de la identidad cultural. Otros de los elementos constitutivos del patrimonio cultural se refieren a la transmisión que ocurre de manera generacional, que se reproduce o recrea según distintas regularidades, y que manifiesta una relación con el entorno y la historia (Unesco, 2013).

El patrimonio es una construcción social que resignifica las prácticas y bienes que participan en la dimensión de la cultura, la cual crea y recrea los organismos de preservación y los colectivos sociales (Álvarez, 2002, p. 14). Según Pierre Nora (citado 
en Álvarez, 2002, p. 11), en las últimas décadas la categoría de patrimonio ha experimentado una explosión que viene desencadenando una metamorfosis en el término. De esta forma, se ha pasado de un patrimonio anclado en la nación, heredado, visible, material y estatal a uno de carácter simbólico, reivindicado e invisible, intangible, social, étnico y comunitario.

De acuerdo con Gonçalves (2005), el patrimonio se caracteriza por tres aspectos principales: la resonancia, la materialidad y la subjetividad. En cuanto a la resonancia, el patrimonio no depende exclusivamente de voluntades políticas o de determinadas instituciones o grupos de individuos. Por el contrario, el patrimonio es el resultado de la "resonancia" que este encuentra con el público, espectador o representante, y de las complejas y dinámicas fuerzas culturales de las cuales emerge. Con relación a la materialidad, este autor asevera que no hay patrimonio sin una dimensión material, dado el uso existente de "técnicas corporales", entendidas en un sentido ambivalente que transita entre lo material y lo inmaterial, y que reúne las dos dimensiones. Respecto a la tercera característica, la subjetividad, Gonçalves considera que hay una relación orgánica e interna entre las formas de autoconsciencia individual y colectiva y el patrimonio. Es un trabajo consciente, deliberado y en constante reconstrucción. De tal manera, el patrimonio media entre los aspectos de la cultura que han sido clasificados como heredados y aquellos que se consideran adquiridos o reconstruidos. Estos aspectos se encuentran entre las dimensiones materiales e inmateriales; lo objetivo y lo subjetivo; el pasado, el presente y el futuro; el alma y el cuerpo; la proximidad y la distancia.

Desde 1996, con el proyecto de turismo cultural en América Latina y el Caribe lanzado por la Unesco, se inició una serie de reflexiones en torno al patrimonio gastronómico. En el documento base se indica que "toda política cultural bien concebida debe asumir que el acto de comer, concebido como una tradición y a la vez como un acto de creatividad, es mucho más que un hecho alimenticio" (citado en Álvarez, 2002, p. 15).

Varios autores (Contreras y Gracia, 2005; De Garine y De Garine, 1998; Douglas, 1996; Fischler, 1995; Harris, 1998; Lévi-Straus, 1981, entre otros) evidencian la complejidad asociada a la alimentación, entendiendo que se refiere a un acto social y cultural cargado por componentes materiales, simbólicos, ecológicos e históricos, entre otros. Inclusive se ha considerado dentro de la categoría de hecho social total de Marcel Mauss, debido a su capacidad para expresar dinámicas sociales de índole económica, política, social, cultural, etc. Y es precisamente la relación entre la comida y la cultura uno de los aspectos que manifiesta las distintas formas mediante las cuales los saberes y prácticas de la alimentación llegan a ser considerados como parte del patrimonio cultural (Menasche, 2011).

Por su parte, González (2010) recuerda que "el patrimonio alimentario engloba, además de los alimentos, objetos, espacios, prácticas, representaciones, expresiones, conocimientos y habilidades, fruto de la acción histórica continuada de comunidades y grupos sociales” (p. 197). Para Matta (2013) el patrimonio alimentario se refiere a

[...] un conjunto de elementos materiales e inmateriales de las culturas alimentarias que se consideran un legado compartido o un bien común. Este patrimonio alimentario incluye productos agrícolas, ingredientes, platos, técnicas, recetas y tradiciones alimentarias. También incluye los modales en la 
mesa, la dimensión simbólica de los alimentos y, en sus aspectos más materiales, los artefactos de cocina y la configuración de la mesa: utensilios, vajilla, etc. (Matta, 2013, párr. 3).

También se resalta que la cocina, al responder a dinámicas culturales específicas que manifiestan un proceso de aprendizaje dentro de un grupo social determinado, representado en las formas de elegir, transformar, consumir y significar los alimentos y la comida, también indica la identidad cultural. Es decir que sus elementos actúan como marcadores étnicos que diferencian a los grupos humanos, ya sea positiva o negativamente (Contreras y Gracia, 2005, p. 455).

Según Maciel (2005), la cocina forma parte de discursos que expresan pertenencia, en otras palabras, una identidad. Esta denota formas de alimentarse culturalmente establecidas, codificadas y reconocidas. Responde a "un conjunto de elementos referenciados en la tradición y articulados en el sentido de constituirla como algo particular, singular, reconocible ante otras cocinas" (p. 50).

Por último, para el Ministerio de Cultura (2012), se deben tener en cuenta los siguientes aspectos: los conocimientos para la valoración y adquisición de los productos necesarios para el consumo y preparación de alimentos; los procesos de transformación y preparación de alimentos; los productos agrícolas empleados; el consumo de los alimentos; la enseñanza de la cocina y el universo simbólico asociado.

\section{Materiales y métodos}

La metodología de esta investigación tiene un enfoque cualitativo-descriptivo, mediante el cual se busca analizar la realidad social vista desde una perspectiva parcial y, para este caso, externa (Molina Díaz, 2004). El procedimiento metodológico se compuso de las siguientes fases:

a) Revisión de fuente secundaria. En particular se revisó documentación publicada por entidades que dentro de sus actividades trabajan para el fomento, la gestión o el reconocimiento de manifestaciones culturales, en particular, gastronómicas.

b) Se realizaron entrevistas semiestructuradas a propietarios y cocineros de restaurantes típicos de la provincia de Yariguíes, a amas de casa de hogares campesinos ubicados dentro de la provincia y a productores agrícolas de productos representativos de la región. Estos grupos de personas formaron parte de la dinámica como portadores de los saberes de la cultura gastronómica de la región. Con tales entrevistas se buscaba obtener información sobre las tradiciones gastronómicas, los productos agrícolas constitutivos de su cocina y, en particular, sobre técnicas culinarias, prácticas y rituales que manifiestan los significados culturales de los productos y la apropiación del mundo culinario tradicional. Las actividades se realizaron entre marzo y junio de 2018. En función de un ejercicio de investigación formativa, los estudiantes del semillero del programa de Gastronomía y Alta Cocina recibieron formación en el "método etnográfico y técnicas para la adecuada observación en campo". Respondiendo a los objetivos de este proyecto, los estudiantes realizaron entrevistas a personas oriundas de los municipios que pertenecen a la provincia de Yariguíes, con el fin de identificar a 
las portadoras de los saberes en cocina tradicional mediante unos criterios establecidos. Una vez identificadas, se priorizó el trabajo con algunas de ellas.

c) Encuentro con las maestras portadoras de los saberes gastronómicos. Aquí las maestras prepararon los platos propios de la región, acompañadas por sus "discípulos", estudiantes que querían aprender sus secretos gastronómicos. En este espacio se entrevistó a las portadoras para identificar la cocina tradicional de la provincia objeto de estudio y sus manifestaciones culturales asociadas. Posteriormente, se realizó un taller de memoria alimentaria, que tuvo como objetivo evocar los sabores y rituales alimentarios, y se buscó relacionarlos con el contexto donde se produjeron.

d) Jornadas de grabación de video: a partir de los hallazgos encontrados, se evidenció que la población de la provincia de Yariguíes, en su mayor parte, está influenciada por el río Magdalena y sus ciénagas. Por esta razón se escogió el municipio de Barrancabermeja para realizar un video que muestre el oficio que realizan los pescadores y, a su vez, que resalte las tradiciones gastronómicas identificadas en el desarrollo de la investigación.

\section{Resultados}

\section{Perspectiva etnohistórica y sociocultural de la alimentación de la provincia de Yariguíes}

En la primera mitad del siglo XX, la conformación poblacional de Barrancabermeja incluía habitantes provenientes de Japón y China, quienes sobresalían en la zona por su diferencia fenotípica, manifiesta principalmente en la forma de sus ojos y su contextura. Otros trabajadores habían llegado de los Estados Unidos y exhibían sus camisas de caqui fuertes y botas ferradas. De igual manera, hacían presencia los alemanes, que eran identificados por su cabeza rasurada, blancos y rojizos. También habían llegado negros de Cuba y hombres de Antioquia y Santander "con sus camisas blancas de seda y su andar ligero" (Vargas, 2001).

Las gentes no se apresuran. Tienen de la vida un concepto que no existe en ninguna otra parte de la república. Lo que se gana es para divertirse. Hay mujeres venidas de los cuatro puntos cardinales de la tierra, pianos de cola y whisky. [...] Sobre la muerte se hacen bromas ácidas y corrosivas. La ciudad es cruel y halagadora. (p. 42).

En ese mismo sentido, sobre el carácter de los barranqueños, De los Ríos (2002) afirma que "eran bravos, fornidos cancamanes que subían y bajaban por el río encaramados en las barcazas, en los planchones y en las casas flotantes que bogaban cantando de nocheluna sin temores, acunados por los vagidos de los caimanes" (p.102). Sobre el acento, afirma que no era caribe, de las Antillas, más bien hablaban como antioqueños, paisas.

Por otro lado, al referirse a su alimentación, esta misma autora comenta: "En Barranca se come [al desayuno] bollo de mazorca con queso recién hecho, y así mismo se comen los bollos de huevos de la hembra del bocachico. Caviar rosa de exquisito sabor y textura" (p. 103). Algunas recetas tradicionales de Barrancabermeja a base de pescado son: sancocho de bocachico con coco de Barrancabermeja, arroz de bocachico salado, 
bocachico guisado con coco, sancocho de cabeza de bagre ahumado y pescado frito crujiente (De los Ríos, 2002).

Por lo que atañe a las costumbres de los pueblos originarios, en la novela La Vorágine, de José Eustasio Rivera (1985), se hace referencia a la forma primitiva como se elaboraba el casabe. Dice la obra en un pasaje que las indias viejas rallaban la yuca para la fabricación del casabe que debía alimentarnos en el desierto. Menciona Torres Almeyda (1970), en "Pipatón y Yarima", sobre los yariguíes y sus costumbres alimentarias: "Son seres trashumantes y pendencieros, altos y ágiles de cuerpo, se pasan la vida comiendo pescado y almacenando carne de oso, báquiros, pumas, aves silvestres, plátanos y yuca, cuando no guerreando o buscando pleito" (p. 105).

Sobre el origen de la población étnicamente diversa que constituye hoy día Barrancabermeja se encontró que

[...] el 7 de noviembre de 1918 se inició la extracción del crudo del pozo Infantas. El traspaso a la Tropical Oil Company se produce en el año en que comienza la verdadera historia del oro negro en Colombia. El Centro se convierte en un hervidero humano proveniente de la Costa Atlántica, Antioquia, Tolima y los dos Santanderes, principalmente. Los afrodescendientes son quienes más resisten el azote de las plagas de mosquitos, las fiebres palúdicas y el ardiente clima, se decía por aquel entonces. (Hernández, 2010, p.101)

Con base en lo anterior, podría decirse que los pobladores del área de estudio de esta investigación adoptaron algunas costumbres y tradiciones gastronómicas de los inmigrantes. Por otro lado, los habitantes de la provincia de Yariguíes tienen su propia identidad social y el respeto por las prácticas y costumbres. Las personas se adaptan y se apropian de los hábitos y tradiciones trasmitidas por antecesores, quienes aprehendieron los saberes a través de la oralidad y, generalmente, desde la infancia. Con ello viene la asimilación cabal de los componentes de la tradición, lo cual garantiza que, a su vez, los saberes sean nuevamente transmitidos a las generaciones futuras.

\section{Saberes empíricos de la cocina tradicional}

Después de la revisión de la bibliografía disponible, para lograr los objetivos propuestos, y con los criterios de selección establecidos, se identificaron las maestras: aquellas personas portadoras de los saberes empíricos de la cocina tradicional, y, por otra parte, sus discípulos: jóvenes a quienes les gustara el arte de la cocina.

En esta dinámica, un grupo transdisciplinar de la UNAB (estudiantes del semillero de investigación y docentes investigadores del programa de Gastronomía y Alta Cocina), junto con la Corporación para la Construcción Participativa de la Salud Pública (Obusinga), organizaron las visitas a los municipios seleccionados: San Vicente de Chucurí, Barrancabermeja y Puerto Wilches, pertenecientes a este núcleo provincial.

Dentro de este proceso se entra a la intimidad de sus cocinas y secretos culinarios, que han sido transmitidos desde el pasado, de generación en generación, de forma oral y mediante el proceso de enseñanza dentro de las labores domésticas cotidianas que tenían en su día a día. Sin embargo, como las mismas maestras dicen: "las chinas de hoy en día 
solo piensan en salir del pueblo y que las mantengan". En este punto, los estudiantes del semillero del programa profesional en Gastronomía y Alta Cocina les manifestaron a las maestras su interés por esta loable y en ocasiones desconocida labor. El estudiante Paul Cañas comenta a este respecto:

En la primera visita realizada en la ciudad de Barrancabermeja compartimos momentos de integración y escuchamos las anécdotas de la niñez de las señoras Claribel Simanca y Rosalía Reyes. Después de esta integración las maestras se dedicaron a enseñarles las técnicas a sus aprendices con el fin de que ellos en un futuro puedan seguir con el legado; de igual manera las personas que hacíamos el papel de observadores aprendimos algunos trucos esenciales a la hora de elaborar un plato, como también a conocer los tipos de peces. (Cañas, 2018).

Continuando con la dinámica, la señora Rosalía nos presentó un plato innovador: una deliciosa picada de pescado, un plato poco común debido a que su mamá fue la que lo inventó para presentarlo en el Festival del Pescado. La picada consistía en trozos de las siguientes clases de pescados: doncella, blanquillo, bocachico y cachama, los cuales se cubrían con una capa de harina y finas hierbas, lo que resaltaba su sabor. Por otra parte, la señora Claribel (Bollirri) compartió la tradicional forma de hacer bollos de coco y el auténtico bollo limpio. Se combinaron las dos preparaciones, lo que dio como resultado un espectacular plato lleno de innovación y tradición.

En el siguiente encuentro, el turno fue para los aprendices, quienes eligieron dos platos típicos de la región y de la ribera del río Magdalena. En el caso de la señora Claribel, su aprendiz preparó una carne molida cocinada en guiso criollo, arroz y una ensalada de papa y huevo. En el caso de la señora Rosalía, sus aprendices optaron por un plato más tradicional: viuda de pescado cocida en hoja de bijao, con acompañamiento de yuca y plátano recolectados a las orillas del río. Al finalizar la degustación, se socializó con las cocineras, quienes quedaron totalmente satisfechas por la labor que habían realizado sus aprendices. Esta actividad demuestra que la transmisión del conocimiento de las tradiciones culinarias mantiene su permanencia a través del tiempo. En cuanto a esto, un estudiante puntualizó: "Esta ha sido una experiencia única donde aprendimos sobre cocina tradicional y autóctona santandereana a través de las preparaciones y las anécdotas de las maestras". Aquí se buscaba identificar no solo los ingredientes de las preparaciones de las distintas etapas de vida de los sujetos participantes, sino también describir las formas como se transformaban los alimentos, las formas como los consumían, los utensilios empleados, los lugares y las situaciones asociadas a la alimentación.

A orillas del río Magdalena está ubicado el municipio de Barrancabermeja. Allí se encuentra el malecón o los puestos del paseo del río, uno de los lugares donde los pobladores y turistas nacionales e internacionales que viajan por este transitado afluente buscan consumir los platos que ofrecen las cocineras y cocineros, la mayoría oriundos de estos territorios. Los platos predominantes en estos puestos de comida son doncella (Ageneiosus pardalis) frita o en sudado, bocachico (Prochilodus magdalenae) fritosudado, bagre (Pseudoplatystoma magdaleniatum) frito-sudado, sopa de cabeza de bagre y las preparaciones que acompañan los platos típicos (arroz, patacón, suero y ñame).

La señora Joaquina, cocinera popular de comida típica, y algunos pescadores cuentan que allí se realiza el Festival de Pescado: 
Esta fiesta nació de la necesidad de aumentar los ingresos de los restaurantes del paseo del río y de incentivar este sitio como turístico. Se hacen concursos como el del arrollador o escamador, pato yuyo (el que coma más pescado en el menor tiempo) y atarrayero (el que coja más pescados con atarraya). (Señora Joaquina, comunicación personal, 2019).

Otro producto que se elabora y se consume es el bollo limpio. Esta es una preparación ancestral a base de maíz blanco, trillado y envuelto en hojas secas de mazorca, para acompañarlo con suero o carnes. Proviene de la costa caribe colombiana, pero fue acogido en poblaciones ribereñas de Santander.

Por otra parte, dentro de las actividades realizadas para el cumplimiento de los objetivos, se hizo un recorrido particularmente por las ciénagas El Llanito, San Silvestre y Paredes y por el río Magdalena. Estas fuentes de agua forman parte del sistema cultural y económico de la región, dado que el oficio predominante es la pesca, en especial con red $\mathrm{y}$ anzuelo, oficio que tienen los pobladores para generar ingresos y realizar sus preparaciones culinarias con pescados como el bocachico, la dorada y el blanquillo.

En la visita a los restaurantes de los hoteles del municipio de Betulia, se encontraron cocineras tradicionales empíricas, aquellas cuya única universidad fueron las abuelas que les heredaron sus mejores recetas y trucos de la cocina colombiana. Uno de los pobladores, el señor Edilberto, invita a conocer el cementerio Guane, de nativos que estuvieron en esta región. Allí mismo brindó en una totuma de "chicha" de sabor fuerte pero dulce y al mismo tiempo con olor a frutas. Durante el recorrido se visitó a Mamá Yiya, como es conocida en el pueblo la mejor cocinera ancestral. En su finca cultiva piña, aguacate, tomate, cebolla y se crían cabros. Ella comenta: "ese es mi mayor truco, cosechar los productos para la preparación del mixto betuliano", plato típico de la región que se compone de cuatro carnes - cabro, pollo, res y cerdo-; es un plato lleno de historia con un trayectoria de 30 años.

También se encontró que al relatar sus historias acerca de los platos y productos que cocinaban sus ancestros (abuelos, madres, tíos y conocidos), los participantes admiten que todos estos saberes fueron transmitidos de forma oral y practicando tanto técnicas como modos de preparación en cada una de sus cocinas. Comentaban que muchas recetas se quedaron en la memoria de quienes dieron origen a la comida santandereana.

\section{De los productos utilizados en la cocina tradicional y sus preparaciones a las prácticas culturales}

La agrícola es una actividad principal de la zona rural de los Yariguíes. Durante el recorrido por los municipios de Barrancabermeja, Sabana de Torres, Puerto Wilches y San Vicente, se pudo observar que en esta provincia se destaca el cultivo de palma de aceite o palma africana, producto agroindustrial que ha traído crecimiento y desarrollo a la región. Sin embargo, en las fincas de pequeños productores agrícolas se observó la siembra de cultivos de pancoger, los cuales proporcionan la materia prima para la gastronomía de la región. 
La señora Yeny Álvarez, cultivadora de aguacate criollo, papelillo, Lorena y Hass, en dos fincas de el Carmen y San Vicente de Chucuri, comenta: "Estos tipos de aguacate son consumidos al interior del país; el aguacate que están sacando para exportar es el Hass [...] las cosechas son en mayo y en noviembre". Así mismo, cuenta que en el Carmen de Chucurí se realiza el Festival del Aguacate, en el que se presentan varias preparaciones con este fruto.

En otra de las visitas a un productor de cacao, este comenta:

Las fincas cacaoteras están en el trabajo de mejorar la calidad en la producción del cacao porque están a la expectativa de "la ruta del cacao", que según el Gobierno departamental pasará por estos municipios. Esto nos ayudará a mejorar la producción y la comercialización no solo del cacao sino de la agricultura. (comunicación personal, 2019).

Estos productores formaron parte del proyecto "Maestras de la cocina tradicional". Así, con sus experiencias, se identificaron los productos que forman parte de las cosechas que producen en la región y que constituyen la cocina tradicional y típica. Esto dio como resultado la caracterización de cada producto y su uso en la gastronomía de la provincia de Yariguíes. A continuación, la tabla 1 presenta las características de productos agrícolas y la tabla 2 las de las preparaciones de la cocina tradicional de la provincia de Yariguíes.

Tabla 1. Características de productos de la provincia de Yariguíes

\begin{tabular}{|l|l|}
\hline \multicolumn{1}{|c|}{ Productos agrícolas } \\
\hline Producto & Características identificadas \\
\hline Aguacate & $\begin{array}{l}\text { Aguacate, aguacate Hass, aguacate papelillo. Se cultivan } \\
\text { principalmente en las zonas rurales de los municipios de San Vicente } \\
\text { de Chucurí y El Carmen de Chucurí. }\end{array}$ \\
\hline Cacao & $\begin{array}{l}\text { Aromático y amargo. El fruto del cacao se caracteriza por tener un } \\
\text { grano de cáscara fina, con alto contenido de manteca. Ha conservado } \\
\text { un estatus importante debido a su uso para la elaboración de } \\
\text { chocolatería fina. Aunque su cultivo se ha popularizado en Colombia, } \\
\text { es originario de México, dado que su proceso de domesticación se } \\
\text { desarrolló en lo que hoy corresponde a ese país. } \\
\text { Algunas investigaciones realizadas en la zona del San Vicente de } \\
\text { Chucurí concluyen que el cacao de la región se caracteriza por su } \\
\text { amplia variabilidad gracias a la interacción con el ambiente y el origen } \\
\text { genético, con "manteca dura", de acuerdo con el perfil de ácidos } \\
\text { grasos, con una alta calidad asociada a sus notas frutales, caramelo y } \\
\text { nuez (Perea Villamil, Martínez Guerrero, Aranzazu Hernández y } \\
\text { Cadena Cala, 2017). } \\
\text { En San Vicente, El Carmen de Chucuri y Yarima, se produce el cacao } \\
\text { (criollo o forastero). Es un producto de finos sabor y aroma. En esta } \\
\text { región lo cultivan familias residentes en fincas o parcelas. "En los } \\
\text { últimos años nos organizamos para realizar un trabajo conjunto para } \\
\text { mejorar la calidad del cultivo utilizando las buenas prácticas en la } \\
\text { cadena de producción", comenta Yeny Álvarez, cultivadora de cacao. } \\
\text { También se cultiva el cacao trinitario (híbrido). Esta variedad de cacao } \\
\text { es producto del cruce entre el cacao criollo y el forastero. Sin embargo, }\end{array}$ \\
\hline
\end{tabular}




\begin{tabular}{|c|c|}
\hline & $\begin{array}{l}\text { por su robustez y calidad lo asemejan más al forastero, aunque tenga } \\
\text { un sabor delicado, rasgo propio del cacao criollo. }\end{array}$ \\
\hline Ñame & $\begin{array}{l}\text { Tubérculo comestible, con contenido alto de carbohidratos complejos } \\
\text { en forma de almidón. Es una raíz de esta planta, de corteza marrón } \\
\text { oscuro y carne comestible, parecida a la batata. El ñame se come asado } \\
\text { o cocido; acompaña a plazo con pescado. Se han identificado otras } \\
\text { preparaciones en el territorio nacional: en sopa, sancocho junto con } \\
\text { yuca, plátano y carne de res o gallina; ñame con queso, cuajada o suero } \\
\text { de leche, con el cual se elabora el mote; en tortas y dulces, } \\
\text { especialmente en época de Semana Santa. }\end{array}$ \\
\hline Plátano & $\begin{array}{l}\text { El plátano es un producto agrícola introducido a América por Jamaica, } \\
\text { sobre todo la variedad dominica. Su cultivo es prospero sobre todo en } \\
\text { toda la zona Caribe, y fue muy aceptado en América debido a sus } \\
\text { propiedades. Se dice que cumplía las mismas propiedades que el maíz } \\
\text { y la yuca. Este rico alimento es preparado de diferentes formas: cocido } \\
\text { en agua, asado a la brasa, en jugos, sopas, asados, fritos y tortas. Hay } \\
\text { gran variedad: bocadillo, pacífico, guineo, hartón dominico, popocho, } \\
\text { entre otros. Las hojas del plátano se emplean para envolturas de } \\
\text { alimentos y conservar y darle un mejor sabor a las preparaciones. }\end{array}$ \\
\hline \multicolumn{2}{|r|}{ Productos del río } \\
\hline Producto & Características identificadas \\
\hline Bagre & $\begin{array}{l}\text { Es altamente apetecido en la gastronomía nacional por la calidad de su } \\
\text { carne y su gran tamaño. Chaves Aguilar (2017) afirma que ha sido un } \\
\text { recurso pesquero sobreexplotado debido al alto valor comercial y la } \\
\text { fuerte demanda que recae sobre la especie (p. 22). Según Mojica et al. } \\
\text { (citados por Chaves Aguilar, 2017), en la década de los setenta } \\
\text { representaba más del } 50 \% \text { de las capturas totales de la subienda. Sin } \\
\text { embargo, para la década de los noventa se presentó un descenso en la } \\
\text { especie causado por la sobrepesca y la alteración negativa de su } \\
\text { hábitat, lo que generó un "empobrecimiento genético y riesgo de } \\
\text { extinción" (Zarate et al., citado por Chaves Aguilar, 2017). En } 2012 \\
\text { fue incluido en la categoría de peligro crítico (CR) (A1d), en el libro } \\
\text { rojo de peces de agua dulce de Colombia (Mojica, et al. 2012, p. 57). } \\
\text { Los pescadores de la región conocen los ritmos y las épocas de pesca } \\
\text { del bagre. Sin embargo, también manifiestan su preocupación por el } \\
\text { descenso tan considerable en el tamaño de los ejemplares que pescan } \\
\text { actualmente. Su posible extinción no solo afectaría la economía local } \\
\text { y la alimentación, sino también el ecosistema en el que habitan, ya que } \\
\text { esta especie regula la población de otras que pueden convertirse en } \\
\text { plagas. }\end{array}$ \\
\hline Bocachico & $\begin{array}{l}\text { El bocachico (Prochilodus magdalenae) es una especie de pez } \\
\text { originario de la cuenca del río Magdalena. Su ciclo de vida transcurre } \\
\text { entre el río y las ciénagas. En épocas de aguas altas prefiere las } \\
\text { ciénagas donde se alimenta de detritus, materia orgánica en } \\
\text { descomposición, mientras que en los periodos de aguas bajas ocurre la } \\
\text { subienda, época en la que este animal va al encuentro del río buscando } \\
\text { los afluentes laterales. Tras llegar a su maduración sexual, y con la } \\
\text { nueva temporada de lluvias, regresa a las ciénagas. En el tránsito de un } \\
\text { lugar a otro realiza el desove en los canales de los ríos. } \\
\text { Las economías campesinas y tradicionales de los habitantes de la } \\
\text { región del Magdalena medio, y en este caso de la zona perteneciente al } \\
\text { departamento de Santander, dependen, en gran medida, de la pesca } \\
\text { artesanal. Tal vez la especie más representativa dentro de esa economía }\end{array}$ \\
\hline
\end{tabular}




\begin{tabular}{|l|l|}
\hline es precisamente el bocachico. Su abundancia y la relación de origen \\
que tiene con el río Magdalena han traído consigo que sea uno de los \\
alimentos fundamentales en la dieta de los pobladores de la zona. En \\
este marco, se evidencia una diversidad significativa de preparaciones \\
culinarias que se elaboran con el bocachico y, además, se ponen en \\
práctica distintas técnicas tradicionales de preparación. \\
De acuerdo con autores como De los Ríos (2002), "quienes han vivido \\
en las márgenes del caudaloso Magdalena y profesan veneración y \\
respeto a su Tritón interior e individual, aman el bocachico y jamás se \\
refieren a él en términos peyorativos" (p. 104). Existe una relación \\
directa entre el bocachico, el territorio y la identidad. Ser pescador es \\
sinónimo de consumir bocachico. No haber probado este alimento y \\
no incorporarlo a la dieta lo aleja del concepto cultural de pescador. \\
Para poder prepararlo y consumirlo es necesario "arrollarlo". Allí se \\
ponen en práctica saberes tradicionales referentes a las técnicas \\
culinarias. Arrollar el bocachico consiste en realizar unos cortes muy \\
finos verticalmente y próximos uno del otro para cortar las espinas, de \\
tal manera que el consumo sea más agradable. \\
Los pobladores de la región también suelen salar el pescado, tanto para \\
conservarlo y consumirlo en sus hogares como para la venta o el envío \\
a otros municipios en los que se comercializa. Para salarlo debe abrirse \\
por la zona de la barriga en corte mariposa, se le agrega la sal y se deja \\
al sol por un par de días, hasta que reduzca considerablemente su \\
cantidad de agua. El pescado salado es el ingrediente principal en \\
preparaciones como la viuda de pescado.
\end{tabular}

Tabla 2. Características de preparaciones de la cocina tradicional de la provincia de Yariguíes

\begin{tabular}{|l|l|}
\hline Producto & Características \\
\hline Arroz con coco & $\begin{array}{l}\text { Esta preparación se heredó de la costa Caribe colombiana, pero se } \\
\text { consume en los hogares y restaurantes de la provincia Yariguíes. Para } \\
\text { su elaboración se debe iniciar fritando el coco rallado en aceite. } \\
\text { Posteriormente, se adiciona el arroz, se revuelve, para luego agregar } \\
\text { azúcar o panela. Pasados cinco minutos, se agrega la leche de coco, } \\
\text { uvas pasas, sal al gusto y agua. Se procede a cocinar a fuego medio } \\
\text { hasta que comience a secar. Se deja tapado, a fuego lento, hasta que } \\
\text { esté totalmente cocinado. }\end{array}$ \\
\hline Arroz de & $\begin{array}{l}\text { Salar el pescado es una técnica tradicional de los pescadores y } \\
\text { bocineras que permiten la conservación del producto de la pesca por } \\
\text { tiempos prolongados. Para preparar este tradicional arroz, que } \\
\text { principalmente se consume en los municipios de Barrancabermeja y } \\
\text { Puerto Wilches, se deben remojar los bocachicos en agua limpia y } \\
\text { fresca para desalarlos. Luego se cocinan en poca cantidad de agua. El } \\
\text { agua que se obtiene de este procedimiento no debe colarse y es } \\
\text { necesario reservarla. Después se sacan los bocachicos para escurrirlos, } \\
\text { retirar la piel con las escamas y desmenuzar su carne. En otro caldero } \\
\text { se debe poner agua con los aliños y aceite para cocinar el arroz, como } \\
\text { lo realiza usualmente, pero incorporando poco a poco el agua que se } \\
\text { había reservado antes. }\end{array}$ \\
\hline
\end{tabular}




\begin{tabular}{|c|c|}
\hline $\begin{array}{l}\text { Arroz de moncholo } \\
\text { ahumado }\end{array}$ & $\begin{array}{l}\text { Una maestra de la cocina de Barranca cuenta que este plato es ancestral } \\
\text { y lo preparaban para época de Semana Santa. Consiste en limpiar el } \\
\text { pescado, sacándole las vísceras. Luego se sala y se lleva al fuego para } \\
\text { asar. Después se pasa por agua caliente, se saca y se deja reposar para } \\
\text { desmenuzarlo y extraerle las espinas. En seguida se prepara el arroz en } \\
\text { el agua donde hirvió el pescado, se agrega leche de coco y sal y se deja } \\
\text { secar. Después de que el arroz se seca, hay que agregar el moncholo y } \\
\text { revolverlo bien. Luego se tapa a fuego lento hasta que termine de cocer } \\
\text { el arroz. }\end{array}$ \\
\hline $\begin{array}{l}\text { Bocachico frito } \\
\text { sudado }\end{array}$ & $\begin{array}{l}\text { Como se mencionó anteriormente, freír el pescado es una estrategia } \\
\text { que han empleado los pobladores de la región como técnica de } \\
\text { conservación de los alimentos. De tal manera que generalmente se } \\
\text { contaba con pescado disponible en las casas aunque no se tuviera } \\
\text { equipos de refrigeración. El lugar al cual se le asocia el origen a esta } \\
\text { preparación es el corregimiento El Llanito. En la actualidad, se elabora } \\
\text { con bocachico que se ha freído en el mismo día en el que se va a } \\
\text { consumir. Después de haberlo escamado y arrollado, se fríe el } \\
\text { bocachico. En un caldero se prepara el guiso con cebolla en rama, } \\
\text { cebolla cabezona, tomate, ají, ajo, cilantro, comino y color; se cocinan } \\
\text { en ese guiso agregando un poco de agua o leche de coco. Esta es una } \\
\text { de las preparaciones que más solicitan los visitantes en los restaurantes } \\
\text { ubicados tanto en el Muelle de Barrancabermeja como en El Llanito. }\end{array}$ \\
\hline $\begin{array}{l}\text { Bocachico guisado } \\
\text { con coco }\end{array}$ & $\begin{array}{l}\text { Otra de las preparaciones con este pescado es el bocachico guisado con } \\
\text { coco. Para ello se espolvorea sal y jugo de limón en las ruedas del } \\
\text { bocachico, las cuales posteriormente se fríen en abundante aceite hasta } \\
\text { que queden bien doradas. Luego se escurren y se dejan reposar. Para } \\
\text { el guiso, se debe usar un caldero o sartén grande, donde se ponen a } \\
\text { sofreír la cebolla, luego el tomate y los ajíes picados. Una vez el guiso } \\
\text { está listo, se colocan las postas de bocachico y ser agrega leche de } \\
\text { coco. Se adiciona sal al gusto. Posteriormente, se cocina a fuego lento } \\
\text { por } 20 \text { minutos hasta que el bocachico se impregne de la salsa. Para } \\
\text { que no se seque, se recomienda agregar agua durante la cocción a fuego } \\
\text { lento. Generalmente se sirve con arroz blanco o yuca cocinada. }\end{array}$ \\
\hline Bollo limpio & $\begin{array}{l}\text { Producto a base de maíz blanco. Se remoja el maíz blanco desde el día } \\
\text { anterior. Hay que realizar una limpieza cuidadosa para retirar todas las } \\
\text { impurezas. Se elimina el agua del remojo y se pone a cocinar en agua } \\
\text { fresca por } 30 \text { minutos. Dejar enfriar, escurrir y proceder a moler el } \\
\text { maíz. Una vez molido, se amasa con un poco de sal hasta obtener una } \\
\text { masa suave y homogénea. En las hojas de mazorca, previamente } \\
\text { lavadas, se ponen tres cucharas de masa, se cubren con otra hoja de } \\
\text { mazorca, se envuelve bien, se doblan los extremos para evitar que la } \\
\text { masa se salga y por último se amarra. Se cocinan en agua hirviendo } \\
\text { durante } 30 \text { minutos aproximadamente. Existe diversidad de bollos. Por } \\
\text { lo general se consume el bollo de mazorca con queso recién hecho, así } \\
\text { como también los bollos de huevas de la hembra del bocachico. }\end{array}$ \\
\hline Dulces & $\begin{array}{l}\text { En la provincia de Yariguíes se elaboran dulces de lenteja, ñame, yuca, } \\
\text { arroz, guandú, coco, mango, papaya, leche cortada, mamón, apio, } \\
\text { papa, arequipe con coco, arroz de leche, entre otros. De acuerdo con la } \\
\text { directora del Festival del Dulce, Nadith López Rocha (Alcaldía } \\
\text { Municipal de Barrancabermeja, 2014, p. 60), la tradición de elaborar } \\
\text { dulces proviene de la "región del río y la costa". }\end{array}$ \\
\hline
\end{tabular}




\begin{tabular}{|c|c|}
\hline $\begin{array}{l}\text { Mote de ñame con } \\
\text { queso }\end{array}$ & $\begin{array}{l}\text { Esta es una preparación que no se encuentra en la oferta de los } \\
\text { restaurantes comerciales, pero que conecta a los habitantes con su } \\
\text { territorio, con su pasado y con sus familias. Para su elaboración se } \\
\text { emplea ñame, agua, queso costeño, suero costeño, tomate, cebolla, ajo, } \\
\text { aceite y comino, sal y pimienta al gusto. Primero se cocina el ñame } \\
\text { hasta que se deshaga y quede un caldo espeso. Paralelamente, se hace } \\
\text { un sofrito con cebolla, tomate, ajo, comino, sal y pimienta. Se agrega } \\
\text { a la olla del caldo de ñame, asimismo se adiciona el queso cortado en } \\
\text { cuadritos. Se baja el fuego y se cocina por } 10 \text { minutos más. Luego se } \\
\text { agrega el suero, se mezcla bien y se retira del fuego (Sánchez y } \\
\text { Sánchez, 2012, pp. 108-109). }\end{array}$ \\
\hline Patacón & $\begin{array}{l}\text { Se utilizan los plátanos verdes sobre, todo el plátano hartón. Para hacer } \\
\text { esta preparación, se cortan los plátanos verdes en trozos, se aplanan y } \\
\text { se fritan. }\end{array}$ \\
\hline Pescado frito & $\begin{array}{l}\text { Una vez el pescado está limpio y se ha "arrollado", hay que } \\
\text { espolvorearle sal y limón y dejarlo reposar unos minutos. Se calienta } \\
\text { el aceite en un caldero o en una paila y se introducen los pescados uno } \\
\text { a uno. Para obtener un pescado más crujiente, se puede espolvorear } \\
\text { harina de maíz. Una vez estén bien dorados por un lado, se deben } \\
\text { voltear y freír por el otro lado. Cuando estén dorados por ambos lados, } \\
\text { se retiran de la paila, se escurren y se sirven con ají, limón y yuca } \\
\text { cocida. } \\
\text { El pescado frito, y en particular el bocachico frito, también hacen } \\
\text { presencia a la hora del desayuno. Quienes lo consumen para esta } \\
\text { comida lo acompañan con yuca cocida, suero, queso fresco y café con } \\
\text { leche. } \\
\text { Freír el pescado permite una conservación por tiempo prolongado. Con } \\
\text { la fritura se transporta con mayor facilidad, no pierde su forma durante } \\
\text { el transporte, se concentra su sabor y responde a las preferencias de la } \\
\text { zona de estudio, en donde sus habitantes afirman preferir el pescado } \\
\text { frito crujiente (De los Ríos, 2002). }\end{array}$ \\
\hline $\begin{array}{l}\text { Sancocho de } \\
\text { bocachico con coco } \\
\text { de } \\
\text { Barrancabermeja }\end{array}$ & $\begin{array}{l}\text { El bocachico debe estar limpio, debidamente arrollado y cortado en } \\
\text { candados. Primero se debe freír hasta que quede bien tostado. Para el } \\
\text { sancocho se debe poner a hervir el agua junto con los aliños. Una vez } \\
\text { hierva, se agrega el bastimento, comenzando por el plátano y } \\
\text { finalizando con la yuca. Cuando estén en su punto, se dispone el } \\
\text { bocachico encima y se agrega la leche de coco. Hay que dejar hervir } \\
\text { por media hora más, revolviendo suavemente, para que no se desbarate } \\
\text { el pescado. Se sirve acompañado de arroz blanco (De los Ríos, 2002, } \\
\text { p. 107). }\end{array}$ \\
\hline $\begin{array}{l}\text { Sancocho de } \\
\text { cabeza de bagre } \\
\text { ahumada }\end{array}$ & $\begin{array}{l}\text { Para preparar este plato se deben haber salado y oreado las cabezas de } \\
\text { bagre previamente. Se pueden dejar un par de días al humo hasta que } \\
\text { se sequen. Sin embargo, una vez se van a emplear para preparar el } \\
\text { sancocho, se deben desalar, lo cual se logra sumergiéndolas en agua } \\
\text { que se cambia varias veces. } \\
\text { Para la sopa de sancocho hay que poner a hervir el agua junto con los } \\
\text { aliños que pueden ser cebolla, ajo picado, sal, cominos y ají dulce } \\
\text { picado, y se ponen a cocinar las cabezas de bagre ahumadas y } \\
\text { desaladas hasta que estén casi a punto de deshacerse. A mitad de la } \\
\text { cocción se agregan los trozos de plátano verde, yuca y ñame. No se } \\
\text { debe dejar reducir, y hay que revolver constantemente para que no se } \\
\text { pegue al fondo de la olla y no se ahúme. Se puede agregar leche de } \\
\text { coco al gusto (De los Ríos, 2002, p. 109). }\end{array}$ \\
\hline
\end{tabular}




\begin{tabular}{|c|c|}
\hline Sancocho trifásico & $\begin{array}{l}\text { Se puede preparar con distintos tipos de carnes. Sin embargo, uno de } \\
\text { los preferidos por los habitantes de la provincia es el que se elabora } \\
\text { con cabeza de bagre ahumada (se aconseja que se realice con tres días } \\
\text { de antelación), hueso o carne salada y gallina, que se deben haber } \\
\text { adobado por lo menos el día anterior. Se ponen a hervir los plátanos en } \\
\text { suficiente agua, junto con cebolla en rama y cabezona, ajo y mazorcas; } \\
\text { luego se desmenuza la cabeza de bagre ahumada y se agrega a la olla. } \\
\text { Posteriormente se echa la carne o el hueso salado, y se deja hervir unos } \\
\text { minutos más para proceder a agregarle la gallina. Tras dejarla hervir } \\
\text { otro rato, se incorpora la yuca, la papa y el ñame para que espese. Las } \\
\text { cocineras tradicionales resaltan que se debe prestar especial atención } \\
\text { al agua que se dispone en la olla para no tener que agregar agua fría en } \\
\text { el proceso de cocción. De acuerdo con su experiencia, lo que ellas } \\
\text { hacen es poner a hervir bastante agua desde un comienzo, luego de } \\
\text { hervir los primeros ingredientes, sacan agua y la reservan para ir } \\
\text { adicionando en la medida que se requiera (Alcaldía Municipal de } \\
\text { Barrancabermeja, 2004). }\end{array}$ \\
\hline Solteras-solteritas & $\begin{array}{l}\text { Hacia la zona más andina, como por ejemplo el municipio de Zapatoca, } \\
\text { también se evidencia una importante presencia de los dulces como } \\
\text { preparaciones gastronómicas tradicionales y como fuente de ingresos } \\
\text { para los habitantes del municipio. Uno de los dulces que más se } \\
\text { destaca, con su color naranja y forma de flor, son las solteras o } \\
\text { solteritas. Si bien son una preparación que tiene su origen en la cocina } \\
\text { árabe, se ha popularizado y adaptado a la región santandereana. Para } \\
\text { su elaboración se emplea harina, agua, azúcar, esencia de vainilla, sal } \\
\text { y colorante, y se fríen en un molde. Se rellenan de arequipe o de dulce } \\
\text { de auyama. }\end{array}$ \\
\hline Suero costeño & $\begin{array}{l}\text { En la Biblioteca Básica de Cocinas Tradicionales de Colombia se } \\
\text { referencia el suero costeño como una tradición característica de las } \\
\text { sabanas de los departamentos de Sucre, Córdoba y Bolívar (Sánchez y } \\
\text { Sánchez, 2012). Sin embargo, en las zonas de influencia del río } \\
\text { Magdalena en la provincia de Yariguíes se ha posicionado como uno } \\
\text { de los elementos fundamentales en las comidas de la población. Su } \\
\text { origen se asocia al labán de Oriente Medio, productos que llegan con } \\
\text { las distintas migraciones a la costa norte del país. De consistencia } \\
\text { cremosa y sabor ligeramente ácido, el suero costeño se elabora a partir } \\
\text { de leche; se pasteuriza al inicio del proceso o puede emplearse leche } \\
\text { ya pasteurizada; se le agrega un ácido como limón o vinagre o se deja } \\
\text { avinagrar, es decir, fermentar. Luego se puede retirar o no parte de la } \\
\text { nata, cuando se nota cuajada, separada del espiche o suero de leche. Se } \\
\text { sirve como acompañante de distintas preparaciones como el bollo, la } \\
\text { yuca, los patacones, entre otros. }\end{array}$ \\
\hline Tamal barramejo & $\begin{array}{l}\text { Es una preparación que contiene arroz, arveja, zanahoria, cebolla larga, } \\
\text { cebolla cabezona, tocino de cerdo, costilla y gallina. Todo esto se } \\
\text { envuelve en hojas de plátano previamente soasadas para que se puedan } \\
\text { moldear. }\end{array}$ \\
\hline Viuda de pescado & $\begin{array}{l}\text { La viuda de pescado es una preparación tradicional que caracteriza a } \\
\text { la región porque incluye los alimentos principales que representan a } \\
\text { los habitantes de la zona baja de la provincia y en general a los } \\
\text { pobladores de la ribera del río Magdalena: el pescado, la yuca y el } \\
\text { plátano, principalmente. En algunos casos, también suele llevar } \\
\text { auyama y otros productos. Sin embargo, no solo es el uso de estos } \\
\text { ingredientes lo que le otorga un valor especial a la preparación, sino }\end{array}$ \\
\hline
\end{tabular}




\begin{tabular}{|l|l|}
\hline también el manejo del pescado salado que, como se mencionó \\
anteriormente, es una técnica ancestral para conservar los alimentos. \\
Así mismo, el uso de hojas para su cocción hace que se considere como \\
un legado muy importante de conexión por el pasado prehispánico. \\
En su preparación debe desalarse el pescado. Para ello hay que dejarlo \\
en agua por un par de horas, la cual se debe cambiar en repetidas \\
ocasiones. Se cortan los palitos que traen las hojas de bijao en su base \\
y se disponen en el fondo del caldero en forma de cuadrícula. Se cubren \\
los palitos con hojas de bijao y se arma una capa de yuca, luego se \\
dispone el plátano, y en la parte superior el pescado envuelto en otra \\
hoja de bijao. Se elabora una "cama" para agregar los ingredientes, que \\
deben quedar completamente tapados de nuevo con hojas de bijao. Se \\
cocina por 20 o 30 minutos aproximadamente (Pinto, 2017). Para esta \\
preparación se puede emplear bocachico, bagre o doncella; el plátano \\
puede ser maduro o verde, de acuerdo con la preferencia del comensal.
\end{tabular}

\section{Gastronomía y folklor}

Gracias a los recorridos, entrevistas y encuentros realizados, se logró identificar que entre las expresiones artísticas y culturales más destacadas por la misma la comunidad se encuentran los festivales gastronómicos y los festivales de bandas. Estas manifestaciones culturales principalmente se llevan a cabo en el municipio de Barrancabermeja, y tienen oferta para casi todas las épocas de afluencia turística en la región que conforma la provincia de Yariguíes (tabla 3).

Tabla 3. Festivales gastronómicos más representativos en la provincia de Yariguíes

\begin{tabular}{|l|l|}
\hline $\begin{array}{l}\text { Feria Bonita de } \\
\text { Bucaramanga }\end{array}$ & $\begin{array}{l}\text { En el Festival de Colonias que se realiza en el marco de feria de la ciudad } \\
\text { de Bucaramanga, generalmente se presentan grupos artísticos, tamboras } \\
\text { y flauteros del Magdalena Medio, que acompañan a los comensales } \\
\text { mientras consumen las comidas tradicionales de Barrancabermeja, } \\
\text { Puerto Wilches y Sabana de Torres, como el bollo limpio, el pescado } \\
\text { frito sudado, el tamal barramejo, el sancocho trifásico y el sancocho de } \\
\text { cabeza de bagre ahumada. En general, para los pobladores de la } \\
\text { provincia, la música, el baile y la comida son elementos que se } \\
\text { complementan y hacen presencia de forma conjunta en casi todas las } \\
\text { festividades. }\end{array}$ \\
\hline Festival \\
Dulce & del \\
& $\begin{array}{l}\text { El Festival del Dulce nació en 1994 como respuesta a una iniciativa de } \\
50 \text { mujeres habitantes del barrio Las Playas, que se organizaron para } \\
\text { mejorar sus condiciones de vida. Tradicionalmente, acostumbraban a } \\
\text { elaborar dulce de lenteja en fogones de leña para la época de Semana } \\
\text { Santa, ya que este formaba parte de los alimentos permitidos en época } \\
\text { de cuaresma, y generaba un lazo de unión entre familiares, vecinos y } \\
\text { amigos. } \\
\text { En la actualidad, el Festival se realiza una vez al año. En él participan } \\
\text { mujeres, hombres y familias con dulces de todo tipo. Hay presentaciones } \\
\text { musicales y otras actividades familiares. Se reconoce como un espacio } \\
\text { importante para la salvaguardia de la elaboración tradicional de dulces, } \\
\text { pero también permite que productos que generalmente no consumen los } \\
\text { jóvenes y niños regresen a los paladares de grandes y chicos. Por }\end{array}$ \\
\hline
\end{tabular}




\begin{tabular}{|c|c|}
\hline & $\begin{array}{l}\text { ejemplo, las generaciones más jóvenes no consumen ñame, pero en } \\
\text { forma de dulce sí. }\end{array}$ \\
\hline $\begin{array}{l}\text { Festival } \\
\text { Pescado }^{5}\end{array}$ & $\begin{array}{l}\text { Decenas de mujeres que comenzaron trabajando de modo informal, } \\
\text { vendiendo y preparando comida en la ciudad de Barrancabermeja, } \\
\text { fueron reubicadas en lo que hoy se conoce como el Paseo del Río. En su } \\
\text { mayoría, son mujeres que llevan más de cuatro décadas dedicadas al } \\
\text { oficio de la cocina, y que con sus restaurantes deleitan a locales y } \\
\text { visitantes. A orillas del río Magdalena, hace aproximadamente } 17 \text { años, } \\
\text { los propietarios de las } 43 \text { casetas se organizaron y le dieron vida al } \\
\text { Festival del Pescado, momento del año en el que se ofrece una gran } \\
\text { variedad de preparaciones a base de pescado. Durante este festival } \\
\text { también se realiza el concurso de pato yuyo, en el cual los participantes } \\
\text { deben consumir más rápido una cantidad determinada de pescado } \\
\text { (generalmente tres libras) y dejar la cabeza y la cola unidas. También } \\
\text { están los concursos del atarrayero más rápido y del escamador o } \\
\text { arrollador más rápido; en ocasiones deben demostrar su habilidad con } \\
\text { los ojos vendados. }\end{array}$ \\
\hline $\begin{array}{ll}\text { Festival } & \text { del } \\
\text { Sancocho } & \\
\text { Decembrino } & \end{array}$ & $\begin{array}{l}\text { Para los barranqueños el sancocho es una forma de compartir eventos } \\
\text { especiales. Es un medio de cooperación colectiva y una forma de } \\
\text { reunirse con sus allegados. A raíz de ello, nació la propuesta del Festival } \\
\text { del Sancocho Decembrino, cuyo objetivo es hacerle un homenaje a esta } \\
\text { preparación. Anualmente participan por lo menos } 10 \text { cocineros y } \\
\text { cocineras tradicionales, madres cabeza de familia, quienes conforman } \\
\text { equipos y concursan por el mejor sancocho para la comunidad. De } \\
\text { acuerdo con su fundadora y gestora, esta es una forma de salvaguardar } \\
\text { las tradiciones culinarias de Barrancabermeja. }\end{array}$ \\
\hline $\begin{array}{l}\text { Festival del } \\
\text { Sancocho } \\
\text { Levantamuertos }\end{array}$ & $\begin{array}{l}\text { La celebración del día de la Virgen del Carmen es representativa en la } \\
\text { zona de influencia del río Magdalena. Tanto conductores de camiones, } \\
\text { transportadores y particulares como quienes día a día viajan por el río } \\
\text { sienten una gran devoción por esta Virgen, a la que se encomiendan y } \\
\text { conmemoran en su día. Para algunos, esta fiesta va acompañada del } \\
\text { consumo de bebidas alcohólicas, por lo que al día siguiente buscan un } \\
\text { alimento que les permita recobrar las fuerzas perdidas el día anterior. Por } \\
\text { ello es apetecido el sancocho levantamuertos, una preparación que se } \\
\text { elabora con cabeza de bagre, filete de pescado pacora, doncella, } \\
\text { blanquillo, yuca, papa, plátano verde y mafufo, y que sirve para pasar la } \\
\text { resaca o guayabo. De esta forma, desde hace casi una década surgió el } \\
\text { Festival del Sancocho Levantamuertos, momento del año en el que } \\
\text { varias familias y amigos se reúnen para concursar por el mejor sancocho } \\
\text { en la zona de la Rampa de Barrancabermeja, alrededor de una de las } \\
\text { preparaciones más emblemáticas de Colombia. }\end{array}$ \\
\hline $\begin{array}{l}\text { Festival } \\
\text { Gastronómico y } \\
\text { de Colonias }\end{array}$ & $\begin{array}{l}\text { La historia de Barrancabermeja, Sabana de Torres y Puerto Wilches } \\
\text { incluye la llegada de distintos habitantes de los departamentos aledaños } \\
\text { como Sucre, Bolívar, Córdoba y Magdalena, quienes en busca de nuevas } \\
\text { tierras para vivir llegaron a esta zona de Santander. Las tradiciones } \\
\text { gastronómicas conectan a cocineros y consumidores con su identidad }\end{array}$ \\
\hline
\end{tabular}

\footnotetext{
${ }^{5}$ La información empleada para la caracterización de los festivales es del libro Barrancabermeja con mucho gusto (Alcaldía Municipal de Barrancabermeja, 2014).
} 


\begin{tabular}{|l|l|}
\hline & $\begin{array}{l}\text { cultural, en este caso, con la identidad regional. Algunos de estos } \\
\text { migrantes internos se organizaron en la Asociación de Colonias } \\
\text { Residentes en Barrancabermeja (Asocoba). En 2004, este grupo, y como } \\
\text { hijo del Festival de Bandas, fomentó un festival en el que se reúnen } \\
\text { preparaciones propias de sus territorios de origen. En la actualidad, allí } \\
\text { se dan cita no solo colonias de los departamentos mencionados } \\
\text { anteriormente, sino también de otras regiones del país que hacen } \\
\text { presencia en este municipio. }\end{array}$ \\
\hline $\begin{array}{l}\text { Festival Nacional } \\
\text { del Bollo }\end{array}$ & $\begin{array}{l}\text { Los bollos son una preparación que tiene su origen en las comunidades } \\
\text { indígenas prehispánicas, que cocinaban distintas masas de maíz } \\
\text { envueltas en hojas. Con el paso del tiempo, se ha ido diversificando y se } \\
\text { encuentra presente en casi todo el territorio nacional, con sus distintas } \\
\text { características particulares. En Barrancabermeja, un grupo, } \\
\text { principalmente de mujeres que fueron reubicadas en el barrio La } \\
\text { Victoria, debido a las inundaciones del barrio Cardales y que mantenían } \\
\text { a sus familias elaborando yendiendo bollos, crearon la Asociación de } \\
\text { Bolleras Barrio La Victoria (Asobavic), y en 1997 lograron } \\
\text { institucionalizar el Festival Nacional de Bollo, que se realiza } \\
\text { anualmente. Allí se puede encontrar el representativo bollo limpio, el } \\
\text { bollo de plátano, el de yuca, el esponjado, el de huevos de pescado, las } \\
\text { hallacas de mazorcas, entre otros. Las mujeres que han participado desde } \\
\text { sus inicios llevan más de cuatro décadas dedicadas a este importante } \\
\text { oficio. }\end{array}$ \\
\hline
\end{tabular}

\section{Producción audiovisual como aporte a la salvaguarda del patrimonio gastronómico}

Teniendo en cuenta estos antecedentes, con los hallazgos de esta investigación se realizó el diseño de un material audiovisual en el que se exalta el oficio del pescador artesanal. En este producto se propone reconocer la cultura material asociada a su desempeño, como la elaboración de la red, las agujas, los anzuelos y las canoas. Así mismo, se busca sensibilizar sobre la cocina tradicional asociada a la pesca como parte de un sistema cultural propio de las ciénagas y los ríos. En la configuración de estas prácticas se expresa la relación con el entorno medioambiental y las tradiciones. Finalmente, como parte del producto audiovisual, se registran algunas preparaciones tradicionales de esta región, rica en su biodiversidad. Aquí sobresale la comida de río, como la picada de pescado, el bocachico frito sudado y el arroz de moncholo salado.

El programa de Gastronomía y Alta Cocina de la UNAB viene juntando esfuerzos institucionales en pro de la salvaguardia del patrimonio gastronómico. Ejemplo de ello es el lanzamiento de la miniserie web Saberes y sabores ${ }^{6}$. Con esta se busca que los platos santandereanos sean registrados mediante testimonios fílmicos, y de este modo propiciar un "rescate de la cocina tradicional" y la preservación de recetas ancestrales.

El capítulo más reciente es un corto titulado Arroz de pescado ${ }^{7}$, resultado de esta investigación. El próximo capítulo será sobre la tradición pesquera de la provincia de Yariguíes. Así mismo, dos estudiantes del semillero de investigación participaron en la

\footnotetext{
${ }^{6}$ Véase al respecto: https://unabtv.com/category/nuestras-producciones/

${ }^{7}$ Véase al respecto: https://www.youtube.com/watch?v=pseoTMw_Z1c\&feature=youtu.be
} 
redacción de un artículo basado en este ejercicio investigativo, que titula "Barrancabermeja y su gastronomía, un tesoro poco explorado" (Cañas Carvajal, Capacho Tirado, García Rodríguez y Holguín Mariño, 2019), el cual publicó la revista La Tercera Orilla, adscrita a la UNAB.

\section{Discusión}

Teniendo en cuenta los objetivos de la investigación se identificó que las costumbres gastronómicas de los pueblos que conforman la provincia de Yariguíes siguen siendo parte de su identidad. También se observó que los productos de las tierras de esa zona del departamento son utilizados en las recetas de sus platos, aunque algunos, como el casabe, producto elaborado con yuca amarga, se han perdido en el tiempo. Otros productos agroalimentarios solo se consiguen según el ciclo del cultivo, es decir, cuando están en cosecha, tiempo en el que son aprovechados para sus preparaciones culinarias, o solo se ofrecen en ciertas ocasiones, tal vez porque la comida tradicional es muy elaborada, lo que requiere tiempo de preparación.

En cuanto a las manifestaciones culturales, en esta provincia los saberes fueron transmitidos de forma oral y práctica por parte de las comunidades ancestrales. En alguna época, los jóvenes no tenían interés de aprender la cocina tradicional. Sin embargo, con los nuevos programas académicos de gastronomía que ofrecen algunas instituciones de educación en Santander, este quehacer se está haciendo más relevante entre las nuevas generaciones. Así mismo, debido al incremento del turismo podría decirse que esto ha llevado a los restaurantes a interesarse en ofrecer las comidas tradicionales, y de esa esa forma dar a conocer su propia identidad.

Por otro lado, y en concordancia con la literatura consultada en documentos de la Unesco, el Ministerio de Cultura y otros autores — de los cuales se tomó referencia en este artículo-, se puede decir que el patrimonio gastronómico de la provincia de Yariguíes se identifica plenamente con los procesos que sugiere el Ministerio de Cultura (2012).

En primer lugar, en dichos procesos se tienen en cuenta los conocimientos para la valoración y adquisición de los productos necesarios en el consumo y la preparación de los alimentos. En la provincia Yariguíes se identificó que las tradiciones gastronómicas manifiestan un saber propio de los habitantes ribereños. Son los pescadores los que conocen los ciclos de los ríos, caños y ciénagas, las épocas de pesca que permiten la sostenibilidad del ecosistema y los momentos del día que son más propicios para esta práctica tradicional. En ese mismo sentido, las maestras reconocen que la experiencia diaria en la cocina y conocer los ciclos de los cultivos de pancoger les ha permitido saber si un alimento es adecuado para la preparación que se vaya a cocer.

En segundo lugar, se destacan los procesos de transformación y preparación de los alimentos. Tanto los pescadores como las maestras han aprendido de sus antecesores técnicas de conservación de los alimentos; un ejemplo de ello es la técnica de salar carne y pescado. Como se mencionó anteriormente, salar estos productos les aseguraba su disponibilidad por un tiempo mayor y facilitaba el transporte de los alimentos. En algunos casos, los pescadores de la provincia continúan realizando esta práctica por necesidad. En la mayoría de los casos esta técnica continúa viva porque se ha instaurado como una forma 
representativa del consumo de los alimentos. Es decir, los habitantes de la provincia buscan la reproducción de estos sabores que ya forman parte de sus preferencias gastronómicas, aunque no sean preparaciones de consumo cotidiano.

En ese mismo sentido, los pescadores son hábiles arrolladores. Su oficio no culmina una vez el pez se encuentra en el anzuelo o en la atarraya, sino que ellos mismos, con sus manos y artefactos, a veces elaborados por ellos, retiran las escamas y cuidadosamente cortan sus espinas para facilitar el consumo; en sus propios términos: "lo arrollan". Saber escamar y arrollar los pescados no es un conocimiento exclusivo de los pescadores, aunque se conecta de forma directa con este oficio.

Las técnicas tradicionales, que favorecen la conservación y el transporte (salar y freír), la producción (técnicas de pesca y trabajo agrícola), la elaboración y transformación (hervir, asar, ahumar, fritar, arrollar) y el consumo, implican una materialidad (Gonçalves, 2005) en la que el empleo de conocimientos abstractos y tangibles se plasman teniendo como medio y fin los mismos alimentos. Tal vez, precisamente, sea el patrimonio gastronómico uno de los ejemplos más notorios en los que se puede ver esta relación entre la materialidad y el valor otorgado a las preparaciones derivadas del uso de estas técnicas. Esa materialidad es efímera en la medida en que una vez se consume la comida solamente queda el recuerdo.

Las maestras de la cocina tienen una gran destreza para alistar los alimentos necesarios en sus preparaciones. Tanto los pescados como los frutos, tubérculos y demás alimentos ponen de manifiesto sus habilidades. Igualmente sucede con las técnicas de cocción o de preparación de los alimentos. Las portadoras partícipes de esta investigación compartieron su conocimiento frente al uso de hojas de plantas para cocinar, como en el caso de la viuda de pescado y los tamales barramejos. En todas sus preparaciones se denota la precisión de sus acciones que cuidadosamente dan origen a un delicioso plato. Esto forma parte del patrimonio de la región, como menciona González (2010): "El patrimonio alimentario engloba, además de los alimentos, objetos, espacios, prácticas, representaciones, expresiones, conocimientos y habilidades, fruto de la acción histórica continuada de comunidades y grupos sociales" (p. 197).

En tercer lugar, sobresalen los productos agrícolas que se identificaron en la región: aguacate, yuca, cacao, arroz, plátano y ñame, y algunas frutas como el mango, el banano y la papaya siguen siendo parte del acompañamiento de las preparaciones que tradicionalmente se consumen de generación en generación.

En cuarto lugar, se destaca el consumo de los alimentos. En la provincia de Yariguíes los alimentos se consumen de manera colectiva. La participación de familiares y amigos al unísono de música y baile se evidencia en la dinámica gastronómica de la región. Ejemplo de ello son los numerosos festivales gastronómicos que se realizan en el municipio de Barrancabermeja, donde se reúnen las preparaciones más representativas de la provincia: pescado, sancocho, dulces y bollos. El consumo también se encuentra asociado a formas culturalmente específicas del orden culinario.

Para los habitantes de la provincia, el pescado debe estar acompañado de un tubérculo como la yuca o el ñame, que se sirven con suero o, en su defecto, puede llevar plátano. Así mismo, el sancocho debe llevar un "buen pique". Es de anotar que el consumo de 
pescado en sus distintas formas de preparación (frito, sudado, frito sudado o en viuda) es generalizado. Según la literatura sobre la región, es posible identificar que entre la dieta de los indígenas yariguíes, principales habitantes de la zona, el pescado ocupaba una posición significativa.

El quinto aspecto de la política del Ministerio de Cultura se refiere a la enseñanza de la cocina. En este sentido, para las maestras el aprendizaje de la cocina se ha hecho a través de la oralidad y la práctica, y el haber tenido que enfrentarse solas a las tareas de la cocina, en la que comenzaron a demostrar el dominio del conocimiento adquirido viendo a sus madres y abuelas. Su oficio no solo lo guardan para ellas, sino que también fomentan el aprendizaje de las hijas y nietas, igualmente mediante la práctica.

A pesar de que muchas portadoras de la cocina tradicional son precavidas y evitan compartir sus secretos de cocina, las maestras le hacen honor a su nombre y, en coherencia con sus preocupaciones acerca de la posible desaparición de la cocina tradicional, durante el desarrollo de este proyecto participaron activamente dando a conocer sus saberes y enseñándole a los estudiantes del Programa.

El sexto aspecto alude al universo simbólico asociado a la preparación y el consumo de los alimentos. De acuerdo con los resultados de la investigación, alcanzar a identificar y comprender el universo simbólico requiere un trabajo mucho más profundo que tenga como objetivo principal el análisis de este componente. Aun así, se alcanza a esbozar la relación del consumo de pescado con lo sagrado, en la medida en que es el alimento principal de momentos de restricción del consumo de ciertos alimentos, como sucede en Semana Santa. Igualmente sucede con los dulces, los cuales tienen como fecha especial para su elaboración esa misma época del año. Con relación al pescado, también existen asociaciones con la fertilidad y el buen desempeño sexual e intelectual. También está asociado a las festividades como la del día de la Virgen del Carmen, Patrona de los Lancheros y Canoeros, labor que cotidianamente desarrollan los pescadores, quienes además incorporan en su concepto cultural e identitario el consumo de bocachico.

También es pertinente mencionar que en este patrimonio gastronómico de la provincia de Yariguíes se reconocen las características del patrimonio cultural inmaterial que resalta la Unesco: tradicional, contemporáneo y viviente a un mismo tiempo, integrador, representativo y basado en la comunidad.

Por un lado, es tradicional, contemporáneo y viviente a un mismo tiempo. Los saberes tanto del oficio de la pesca, como el de la cocina, han sido heredados de sus antepasados. Conservan formas y conocimientos que fueron transmitidos de generación en generación, y no se modifican a pesar del paso del tiempo y de la incorporación y disponibilidad de nuevas tecnologías. Sin embargo, no se cierra completamente a la adaptación y a la invención contemporáneas. Como se mencionó para el caso de la señora Rosalía, a partir de su tradicional aprovechamiento del pescado decide crear un nuevo plato: la picada de pescado. Muchos de las preparaciones culinarias descritas se encuentran fácilmente para el consumo tanto en restaurantes como en el Paseo del Río, o son reproducidos en festivales o en las casas de familia. Por eso es posible afirmar que está vivo, que se recrea en la vida cotidiana y festiva de los pobladores de la provincia. 
Por otro lado, este saber se ha ido construyendo con los habitantes, quienes en distintos momentos históricos han migrado desde la costa Caribe, desde el sur del departamento de Bolívar y desde el oriente antioqueño hacia este territorio, y han optado por esta zona como su nuevo lugar de residencia. Estos migrantes internos traen consigo sus tradiciones gastronómicas y gustos culinarios, que son incorporados en las dinámicas de la provincia y generan una gastronomía particular, lo cual hace de este patrimonio algo integrador.

Así mismo, las manifestaciones del patrimonio gastronómico de la provincia no son un aspecto que sea resguardado por un solo grupo de personas aisladas del resto de la región. Por el contrario, las maestras partícipes de esta investigación son mujeres que "representan" los conocimientos, preferencias, gustos y cualidades de una población significativa de la provincia. Sus saberes se ponen de manifiesto en sus cocinas, las cuales son de conocimiento público y se preocupan porque este patrimonio sea transmitido de generación en generación.

La comunidad se siente representada en las preparaciones que se identificaron. Estas forman parte de sus preferencias alimentarias cotidianas y festivas. Si no las preparan en sus casas, buscan restaurantes cuyos menús incluyan estos platos. La gestión que anualmente se realiza para la permanencia y buen desarrollo de los festivales gastronómicos es una muestra de la importancia que tiene el patrimonio gastronómico para la comunidad, ya que esta es una ocasión para consumir los platos y también para generar cohesión social y consolidar lazos de fraternidad y solidaridad.

De tal modo, se evidencia que en la región de Yariguíes el patrimonio gastronómico tiene distintos actores que desempeñan un papel importante en su reproducción y visibilidad. Los creadores y gestores de los festivales, los productores de alimentos y las maestras se articulan a las instituciones y representan los colectivos sociales, respectivamente. Pero también son quienes le dan resonancia, en los términos de Gonçalves (2005). Por ejemplo, en el caso del Festival del Dulce, las mujeres se organizaron y eligieron, entre otras posibilidades, potencializar un saber tradicional para mejorar sus condiciones socioeconómicas, pero también para mostrar ese conocimiento mediante el cual se aprovecha la riqueza regional de los alimentos. Siguiendo la propuesta de este autor, también se resalta que las acciones que permiten reproducir los platos se logran mediante las actitudes conscientes de las maestras, los productores y los gestores, quienes de manera deliberada se preocupan por la continuidad de las manifestaciones culturales asociadas a la comida.

\section{Conclusiones}

Esta investigación permitió identificar y caracterizar parte del patrimonio gastronómico de la provincia de Yariguíes (antes Mares) a través de un trabajo formativo en el cual se fortalecieron las competencias investigativas de los estudiantes del programa de Gastronomía y Alta Cocina de la UNAB. Como se mencionó al inicio de este documento, se desarrolló un proceso de capacitación para los estudiantes del Programa, en torno a las habilidades y condiciones necesarias para realizar un adecuado proceso de observación participante dentro del trabajo de campo que compete al proceso investigativo en mención. 
El proceso de la investigación también contribuyó a la salvaguardia de este patrimonio mediante la transmisión del conocimiento que se propició en las distintas jornadas, en la cuales las Maestras portadoras de los saberes les enseñaban a sus aprendices, o discípulos, esta vez estudiantes del Programa.

La gastronomía de la provincia de Yariguíes está enmarcada en los productos que le aporta el ecosistema conformado por ríos, caños y ciénagas. Es así que existen varios tipos de peces que son fuente de alimentación y la base de los platos tradicionales de esta provincia.

Las economías campesinas y tradicionales de los habitantes de la región del Magdalena Medio dependen, en gran medida, de la pesca artesanal. Tal vez las especies más representativas dentro de esa economía sean el bocachico y el bagre.

Los productos que se cultivan en esta región como el aguacate, el ñame, la yuca, el plátano y las frutas, entre otros, forman parte de los platos preparados por las familias y los restaurantes típicos de la provincia de Yariguíes.

Se logró identificar que entre las expresiones artísticas y culturales más destacadas por la misma comunidad se encuentran los festivales gastronómicos y los de banda, escenarios en los cuales se ofrece variedad de preparaciones gastronómicas, platos elaborados que conectan a los habitantes con su territorio, con su pasado y con sus familias, lo cual crea situaciones de cohesión social. Así mismo, los saberes asociados a la obtención y la transformación de los alimentos representan esa estrecha relación de los pobladores con el medioambiente donde habitan.

Se demuestra, entonces, que el patrimonio gastronómico está asociado a los productos regionales o ingredientes principales (agrícolas o de pesca), a los conocimientos y técnicas tradicionales para la adquisición y transformación de la materia prima en alimento, a un universo simbólico y a las acciones directas o indirectas de los distintos actores (portadores o gestores) que, ante la evidencia del proceso de debilitamiento y pérdida de los saberes, sabores y prácticas, buscan su permanencia y trasmisión generacional.

Finalmente, a partir de los hallazgos de la investigación se propuso la filmación de un video institucional de divulgación abierta, mediante una plataforma digital que contribuya a la salvaguardia del patrimonio gastronómico de la provincia de Yariguíes. Este queda registrado y es de fácil acceso para quienes quieran consultarlo.

\section{Agradecimientos}

A la corporación Obusinga, a las maestras de la cocina, a los docentes investigadores y estudiantes del semillero de investigación de Gastronomía y Alta Cocina, al programa de Audiovisuales de la UNAB y a los portadores de la cocina tradicional mencionados en este documento. 


\section{Referencias}

Alcaldía Municipal de Barrancabermeja (2014). Barrancabermeja, con mucho gusto. Barrancabermeja: Alcaldía Municipal de Barrancabermeja.

Álvarez, M. (2002). La cocina como patrimonio (in)tangible. Temas de Patrimonio Cultural, 6, 11-25.

Cañas, P. (2018). Informe de trabajo de campo. Barrancabermeja: inédito.

Cañas Carvajal, P. D., Capacho Tirado, D. F., García Rodríguez, H. L. y Holguín Mariño, M. J. (2019). Barrancabermeja y su gastronomía, un tesoro poco explorado. La Tercera Orilla, (22), 119-129. Doi: 10.29375/21457190.3705

Carnegie-Williams, R. (1990). Un año en los Andes o aventuras de una lady en Bogotá. Bogotá: Academia de Historia de Bogotá.

Contreras, J. y Gracia, M. (2005). Alimentación y cultura: perspectivas antropológicas. Barcelona: Ariel.

Chaves Aguilar, N. L. (2017). Evaluación de variabilidad de las manchas melánicas del bagre rayado (Pseudoplatystoma magdaleniatum) en la cuenca del Magdalena (tesis de maestría). Universidad Nacional de Colombia, Bogotá, Colombia.

De Castellanos, J. (1857). Elegías de varones ilustres de Indias. Vol. 4. Rivadeneyra. Madrid, España.

De Garine, I. y De Garine, V. (1998). Antropología de la alimentación: entre naturaleza y cultura. Alimentación y Cultura. Actas del Congreso Internacional, 1, 13-34.

De los Ríos, E. (2002). La cocinanza comedida. Gastronomía santandereana, vol. 3. Bucaramanga, Santander: Universidad Autónoma de Bucaramanga.

Douglas, M. (1995). Las estructuras de lo culinario. En J. Contreras (Coord.), Alimentación y cultura: necesidades, gustos y costumbres (pp. 171-198). Barcelona: Universidad de Barcelona.

Fernández de Oviedo, G. (1950). Sumario de la natural historia de las Indias. México: Fondo de Cultura Económica.

Fischler, C. (1995). El (h) omnívoro. El gusto, la cocina y el cuerpo. Barcelona: Anagrama.

Gonçalves, J. R. S. (2005). Ressonância, materialidade e subjetividade: as culturas como patrimônios. Horizontes antropológicos, 11(23), 15-36.

González, I. (2010). La dieta mediterránea como objeto patrimonial. Quaderns de la Mediterrània, 13, 197-201.

Harris, M. (1998). Vacas, cerdos, guerras y brujas. Madrid: Alianza.

Hernández, C. N. (2010). Colombia Santander Geografía de los afectos. Bogotá: Panamericana Formas e Impresos.

Holton, I. F. (1981). La Nueva Granada: veinte meses en los Andes. Bogotá: Banco de la República.

Lévi-Strauss, C. (1981). El origen de las maneras de mesa. México: Siglo XXI.

Le Moyne, A. (1969). Viaje y estancia en la Nueva Granada. Vol. 92. Ediciones Guadalupe. Madison: Universidad de Wisconsin

Maciel, M. E. (2005). Olhares antropológicos sobre a alimentação: identidade cultural e alimentação. En A. M. Canesqui y R. W. D. García (Coords.), Antropologia e nutrição: um diálogo possível (pp. 49-55). Río de Janeiro: Fiocruz.

Matta, R. (2013). Valuing native eating: the modern roots of Peruvian food heritage. Anthropology of Sood, (S8), 1-20. 
Menasche, R. (2011). Cuando la comida se convierte en patrimonio: puntualizando la discusión. Recuperado de https://www.researchgate.net/profile/Renata_Menasche2/publication/260334451 _Cuando_la_comida_se_convierte_en_patrimonio_puntualizando_la_discusion/1 inks/00b7d530ca314d1cd5000000/Cuando-la-comida-se-convierte-enpatrimonio-puntualizando-la-discusion.pdf

Ministerio de Cultura. (2012). Política para el conocimiento, la salvaguardia y el fomento de la alimentación y las cocinas tradicionales de Colombia. Bogotá: Ministerio de Cultura.

Mojica, J. I., Usma, J. S., Álvarez-León, R. y Lasso, C. A. (Eds). (2012). Libro rojo de peces dulceacuícolas de Colombia. Bogotá: Instituto de Investigación de Recursos Biológicos Alexander von Humboldt-Instituto de Ciencias Naturales de la Universidad Nacional de Colombia-WWF Colombia-Universidad de Manizales.

Molina Díaz, C. (2004). Guía metodológica para formular proyectos de investigación educacional. Santiago de Chile: Ministerio de Educación.

Mollien, G. T. (2007). El viaje de Gaspard-Théodore Mollien por la República de Colombia en 1823. Bogotá: Biblioteca Popular de Cultura Colombiana.

Ordóñez, C. (2012). Gran libro de la cocina colombiana. Bogotá: Ministerio de Cultura

Perea Villamil, A., Martínez Guerrero, N., Aranzazu Hernández, F. y Cadena Cala, T. (2017) Características de calidad del cacao de Colombia. Catálogo de 26 cultivares. Bucaramanga: Universidad Industrial de Santander-Federación Nacional de Cacaoteros.

Pinto, H. (28 de octubre de 2017). Viuda de pescado. El toque colombiano (Blog). Recuperado de http://www.eltoquecolombiano.com/2017/10/viuda-depescado.html

Querol, M. Á. (2010). Gestión del patrimonio cultural. Madrid: Akal.

Rivera, J. E. (1985). La vorágine. Santiago de Chile: Ercilla.

Rodríguez-Martínez, L. M., y Cáceres-Flórez, W. A. (2016). Salvaguarda del patrimonio cultural gastronómico santandereano. Jangwa Pana, 15(1), 43-57.

Saffray, C. (1948). Viaje a Nueva Granada. Bogotá: Biblioteca Popular de Cultura Colombiana.

Saldarriaga, G. (2012). Alimentación e identidades en el Nuevo Reino de Granada. Siglos XVI y XVII. Bogotá: Ministerio de Cultura.

Sánchez, E. y Sánchez, C. (2012). Paseo de olla. Recetas de las cocinas regionales de Colombia. Bogotá: Ministerio de Cultura.

Simón, F. P. (1881). Noticias historiales de la conquista de tierra firme en las Indias Occidentales. Bogotá: Casa Editorial de Medardo Rivas.

Steuart, J. (1989). Narración de una expedición a la capital de la Nueva Granada y residencia allí de once meses (Bogotá en 1836-37). Bogotá: Academia de Historia de Bogotá.

Torres Almeyda, L. (1970). Pipatón y Yarima. Vanguardia Liberal. Leyenda popular santandereana. Bucaramanga: Editorial Vanguardia.

Unesco. (2013). Convención para la salvaguardia del patrimonio cultural inmaterial. París: Unesco.

Vargas Osorio, T. (2001). La ciudad junto al río. En: T. Vargas Osorio y S. Agelvis (2001), Santander, alma y paisaje (pp. 39-48). Bucaramanga: Editorial UNAB. 